\title{
Demographic, Psychological, and School Environment Correlates of Bullying Victimization and School Hassles in Rural Youth
}

\author{
Paul R. Smokowski, Katie L. Cotter, Caroline Robertson, and Shenyang Guo \\ University of North Carolina at Chapel Hill, School of Social Work, CB No. 3550, 325 Pittsboro Street, Chapel Hill, \\ NC 27599-3550, USA \\ Correspondence should be addressed to Paul R. Smokowski; smokowsk@email.unc.edu
}

Received 25 February 2013; Revised 26 April 2013; Accepted 20 May 2013

Academic Editor: John McCluskey

Copyright (c) 2013 Paul R. Smokowski et al. This is an open access article distributed under the Creative Commons Attribution License, which permits unrestricted use, distribution, and reproduction in any medium, provided the original work is properly cited.

\begin{abstract}
Little is known about bullying in rural areas. The participants in this study included 3,610 racially diverse youth (average age $=12.8$ ) from 28 rural schools who completed the School Success Profile-Plus. Binary logistic regression models were created to predict bullying victimization in the past 12 months, and ordered logistic regression was used to predict school hassles in the past 12 months. Overall, $22.71 \%$ of the sample experienced bullying victimization and school victimization rates ranged from $11 \%$ to $38 \%$. Risk factors for bullying victimization included younger students and students experiencing depression and anxiety. Being female, Hispanic/Latino or African American, was associated with lower bullying victimization. Thirty-nine percent of the sample reported a high level of school hassles. Younger students and students with higher levels of anxiety and depression were at increased risk for school hassles. Students from larger schools reported high levels of school hassles, while students from schools with more teachers with advanced degrees reported fewer school hassles.
\end{abstract}

\section{Introduction}

According to The National School Safety Center, bullying is the most enduring and underrated problem in US schools $[1,2]$. In a nationally representative sample, nearly $30 \%$ of students surveyed reported being involved in bullying in the current term, either as a perpetrator or a victim [3]. A more recent study found that prevalence rates for the past two months varied by type of bullying: $20.8 \%$ of students surveyed were involved in physical bullying, $53.6 \%$ in verbal bullying, $51.4 \%$ in relational bullying, and $13.6 \%$ in cyber bullying [4].

Bullying is a form of aggression in which one or more children intend to harm another child who is perceived as being unable to defend himself or herself [5]. Many researchers define bullying by four central features $[6,7]$ : intention (i.e., the perpetrator intentionally uses bullying to establish dominance or maintain social status) $[8,9]$, power imbalance (i.e., the bully is physically and/or psychologically more powerful than the victim) [3], repetition (i.e., the bullying occurs repeatedly over time) [3], and provocation (i.e., the victim does not provoke the bully).
Bullying behaviors include name-calling, physical assault, threatening, stealing, defacing personal property, writing harmful statements, spreading rumors, intentional exclusion, extortion, and taunting [1]. Regardless of the chosen behavior, bullying is characterized by intense intimidation that creates a pattern of humiliation, abuse, and fear for the victim [9].

While research on bullying has burgeoned in recent years, little is known about bullying in rural areas. The significant emotional, academic, and physical consequences associated with bullying in general [10], coupled with risk factors unique to rural youth [11], underscore the importance of garnering an increased understanding of bullying in rural populations. Several researchers have applied an ecological framework to study the multiple contexts of bullying and victimization (e.g., [12-14]).

Ecological Theory organizes the environment in terms of micro-, meso-, macro-, and chronosystems [15]. In the current study, the micro- and macrosystems are particularly salient. The microsystem refers to an individual's immediate environment; for adolescents, the microsystem often consists 
of family, peer group, and school [15]. Interactions across these microsystems (i.e., proximal processes) influence one another reciprocally $[15,16]$. This suggests that an adolescent's bullying victimization and school hassles are likely impacted by other proximal processes in the microsystem (i.e., family, peer group, and school). An ecological framework underscores the need to consider the overarching macrosystem, which refers to the social beliefs and norms of a given environment [17]. In the current study, the macrosystem is the rural environment.

Little research has been conducted on health-related risk and protective factors for youth in rural settings [1822], especially regarding the correlates of bullying. The bullying research base has been dominantly devoted to urban youth $[23,24]$. There is a common misperception that rural living is "tranquil" and "peaceful" [25], when in reality, rural life has many complications (e.g., geographic isolation, minimal community resources, and lack of public transportation) absent in urban environments [26]. Rural youth are significantly more likely than urban and suburban youth to smoke, drink alcohol, use drugs, bring a weapon to school, and have sexual intercourse [11]. And one study found that rural youth had significantly more externalizing and internalizing behaviors than urban youth [27]. These additional stressors and risk factors may impact the school and bullying experiences of rural youth.

Although prevalence rates of bullying in rural, urban, town, and suburban areas are equal, $3 \%$ to $5 \%$ more rural youth reported ever bullying than youth in urban, town, and suburban areas [3], indicating that rural youth may be at an increased risk for involvement in bullying. Carlson found that rural youth reported witnessing the most violence and experiencing the highest level of victimization at school compared to their home and neighborhood [18]. Based on past research, it seems that rural schools may have unique risk factors that impact bullying. We must expand our research focus to develop our understanding of the correlates of bullying in rural settings. The extant literature focuses on urban and suburban youth and is synthesized below.

Although victims, bullies, bully/victims, and bystanders are all affected by bullying interactions, the negative effects for victims are quite noteworthy [28], especially in regard to mental health outcomes. Victims have reported feeling ugly, worthless, lonely, and unhappy [10], which might explain why many victims reported low self-esteem $[29,30]$. Various studies have also suggested that victimization was correlated with internalizing disorders [31-34], such as anxiety and depression $[35,36]$. Although bully/victims and bullies are typically more aggressive than victims, victims scored higher than noninvolved youth on a measure of reactive aggression [37], suggesting that victimized youth are also at an increased risk of displaying aggressive behaviors. These mental health outcomes indicate the importance of social support for victims of bullying.

Social support facilitates coping with stressful situations [38]. For example, one study found that the relationship between victimization and poor quality of life was moderated by peer support (i.e., increased levels of peer support decreased the impact of victimization on poor quality of life)
[39]. This suggests that social support serves as a protective factor for victims of bullying. However, extant research indicates that victims of bullying tend to report lower social support, including lower teacher support [40], peer support [40-42], and maternal support [42] than their nonvictimized counterparts. In addition to social support in the microsystem, in line with ecological theory, the macrosystem (e.g., school context) must be considered.

Bullying often occurs at school $[1,5]$. One study found that $7 \%$ of American eighth graders missed school at least one day per month due to bullying [43]. For those students who regularly attend school, at least $20 \%$ of them reported being scared [44] or avoiding restrooms due to bullying [5]. It follows that victims would report a more negative sense of school climate, bonding, and engagement. Indeed, victims in elementary, middle, and high school reported lower school connectedness [45] and higher school dissatisfaction [46] than youth not involved in bullying. However, in another study of 11,033 sixth through tenth graders, there were no significant differences between victims of traditional bullying and non-involved youth in terms of school satisfaction [47], indicating the need for further research. Additionally, researchers must understand how the school environment impacts bullying victimization.

Little is known about the school characteristics associated with bullying, especially for rural schools. Although one study found that victimization varied primarily by individual characteristics rather than by school characteristics [48], further investigation of the relationship between school characteristics and bullying victimization is warranted. School size may be an important factor in the frequency of bullying victimization, and, generally, students felt less safe in larger schools [49]. Some studies have suggested that larger schools have higher levels of violence [50], crime [51], and vandalism [52]. Perhaps these findings can be explained by the fact that increasing school size was related to decreasing student attachment to school, teachers, and extracurricular activities [53]. In line with the above research, researchers have also found that larger schools have higher rates of bullying [54]; however, other studies have suggested no significant relationship between school size and the prevalence of bullying $[55,56]$.

In addition to school size, there are a number of other important school characteristics that may impact victimization and bullying. For example, Wynne and Joo found that academic achievement is an important predictor of criminal victimization and every one unit increase in grades (e.g., B to $A$ ) reduced the likelihood of criminal victimization by 17\%; thus, high academic achievement may also be related to bullying victimization [57]. However, other researchers found that academic performance had no significant impact on the level of nonphysical bullying [58]. Socioeconomic status might also impact bullying, as researchers have found that elementary schools with a high number of low-income students (as measured by free/reduced price lunch) had higher rates of bullying $[59,60]$.

The overarching research question for the current study was what demographic, psychological, social, and school 
factors are associated with bullying victimization and experiencing school hassles. Based on ecological theory we hypothesized the following.

(1) Proximal microsystem influences (i.e., social support and school satisfaction) will be inversely associated with bullying and school hassles.

(2) Distal microsystem influences (i.e., school characteristics) will have less impact on bullying and school hassles than the proximal microsystem influences; however, these school characteristics will form crosslevel interactions with individual characteristics.

(3) Student psychological factors (i.e., depression, anxiety, and aggression) will be positively associated with bullying and school hassles, while self-esteem will be inversely associated with bullying and school hassles.

\section{Methods}

2.1. Current Study. The current study was funded by a cooperative agreement between the United States Centers for Disease Control and Prevention and the North Carolina Academic Center for Excellence in Youth Violence Prevention (NC-ACE). The current sample came from the Rural Adaptation Project (RAP), a five-year longitudinal panel study of more than 4,000 middle school students from 28 public schools in two rural, economically disadvantaged counties within the Southeastern United States. The aim of the larger longitudinal study is to reduce rates of youth violence. The data for the current study were baseline data collected in spring of 2011. The sample from one county included all middle school students enrolled in the 11 public schools in the county. The second county was geographically bigger than the first county and had a much larger student population; thus a random sample of $40 \%$ of 6 th through 8 th graders from the 19 public middle schools was included in this study. Parents from County 2 received a letter explaining the study. If they did not want their child(ren) to participate, they sent a letter requesting nonparticipation and their child was removed from the study roster. Three parents sent letters of refusal. Students assented to participate by reading and electronically signing an assent screen prior to completing the online assessment. In both counties, students were given the opportunity to decline participation; 35 students declined to participate in the study. Participants completed the online assessment in school computer labs with close supervision by research staff, and every student had an identification number that was attached to his or her assessment in order to maintain confidentiality.

2.2. An Impoverished Rural Context. Examining the current rural macrosystem illuminates the environmental stressors present in participants' lives. Both counties have limited public transportation services, which is problematic given the wide dispersion of people (i.e., average population density per square mile of the two counties is 101.65) [61] and resources. Additionally, the nearest large city is about 100 miles from both counties, making it difficult for residents to access metropolitan resources (e.g., a large hospital). Infant mortality is often used to gauge the overall health of a community [62], and in 2011 the average infant mortality rate of the two counties was 9.65 per 1,000 live births [63], which is above the national average of 6.61 [64]. Unemployment in the two counties is also higher than the national average, with an average unemployment of $12 \%$ [65]. Finally, the racial and ethnic composition of these counties is quite rare for a rural community [66]. Both counties in this study are minoritymajority [61].

2.3. Participants. The participants $(N=4,321)$ for this study were from two rural counties in a Southeastern state. Fifty-three percent $(N=2,290)$ of the sample was female. Participants were racially diverse: $28 \%(N=1,210)$ identified as American Indian/Native American, 22.5\% $(N=972)$ identified as non-Hispanic White, $22 \%(N=951)$ identified as non-Hispanic African American, $12 \%(N=519)$ identified as Hispanic/Latino, and 11\% $(N=475)$ identified as mixed race or other. The mean age was 12.8 years. Participants were in middle school (6th-8th grade) and roughly $33 \%$ came from each grade. Sixty-six percent of the participants received a free/reduced price lunch. Additional information about the sample is provided in Table 1.

2.4. Independent Measures. The School Success Profile (SSP) [67] is a 220-item youth self-report survey that measures attitudes and perceptions about school, friends, family, neighborhood, self, and health/wellbeing. Since its creation in 1993, the SSP has been administered to tens of thousands of students, and its reliability and validity are well documented [68]. The current study used a modified version of the SSP, the School Success Profile Plus (SSP+), which included 152 of the original SSP items and two additional subscales: a modified version of the Rosenberg self-esteem scale [69] was used to measure self-esteem, and two subscales from the Youth SelfReport (i.e., child version of the Child Behavior Checklist [CBCL]) [70] were used to measure anxiety and aggression. Each measure is described in detail below.

2.4.1. Demographics. Receiving free or reduced lunch at school was a proxy for socioeconomic status. Race and ethnicity were coded as four dichotomous variables: Hispanic, non-Hispanic African American, American Indian, and mixed race or other. Non-Hispanic White students were the reference group. Gender was a dummy variable and male was the reference group.

2.4.2. Psychological Factors. Depression was measured using four items taken from the SSP [67]. Example items included "I often feel sad" and "I often feel all alone in the world." The Cronbach's alpha reliability for this scale was 0.87 in this sample. The rigorously tested Youth SelfReport has been used extensively with a variety of different communities [71], and two modified subscales were used to measure anxiety and aggression. Anxiety was measured with three items from the original Anxiety subscale from the YSR [70]. The scale items were "I often worry about my future," "I often feel nervous 
TABLE 1: Sample descriptive statistics and model-estimated odds ratios for bullying victimization.

\begin{tabular}{|c|c|c|c|}
\hline \multirow{2}{*}{ Variable } & \multicolumn{2}{|c|}{ Descriptives } & \multirow{2}{*}{ Odds ratio } \\
\hline & Mean & $\mathrm{SD}$ & \\
\hline \multicolumn{4}{|l|}{ Student demographics: } \\
\hline Age & 12.833 & 1.068 & $0.720^{* * *}$ \\
\hline \multicolumn{4}{|l|}{ Gender (male) } \\
\hline Female & 0.532 & 0.499 & 0.866 \\
\hline \multicolumn{4}{|l|}{ Use free or reduced lunch (no) } \\
\hline Yes & 0.664 & 0.473 & 1.063 \\
\hline \multicolumn{4}{|l|}{ Race (non-Hispanic White) } \\
\hline Hispanic & 0.121 & 0.326 & $0.722^{*}$ \\
\hline Non-Hispanic African American & 0.221 & 0.415 & $0.585^{* * *}$ \\
\hline American Indian & 0.278 & 0.448 & 0.825 \\
\hline Mixed race or other & 0.111 & 0.314 & 0.824 \\
\hline \multicolumn{4}{|l|}{ Student psychological factors: } \\
\hline Anxiety & 1.475 & 0.558 & $1.514^{* * *}$ \\
\hline Depression & 1.447 & 0.565 & $1.764^{* * *}$ \\
\hline Aggression & 1.336 & 0.361 & 0.992 \\
\hline Self-esteem & 2.712 & 0.437 & 0.966 \\
\hline \multicolumn{4}{|l|}{ Microsystem factors: } \\
\hline School satisfaction & 2.370 & 0.486 & $0.483^{* * *}$ \\
\hline Friend support & 2.490 & 0.553 & $0.774^{* *}$ \\
\hline Teacher support & 3.166 & 0.563 & 1.160 \\
\hline Parent support & 2.679 & 0.492 & 1.139 \\
\hline Neighborhood support & 3.031 & 0.605 & 0.935 \\
\hline \multicolumn{4}{|l|}{ School aggregated characteristics: } \\
\hline School size & 509.030 & 236.214 & 1.000 \\
\hline$\%$ Students at or above grade level in reading & 57.951 & 9.248 & 0.989 \\
\hline$\%$ Students at or above grade level in math & 75.297 & 7.003 & 1.004 \\
\hline Teacher turnover rate $(\%)$ & 11.303 & 8.968 & 0.992 \\
\hline Teachers with advanced degrees (\%) & 23.438 & 8.556 & 1.004 \\
\hline$\%$ White students & 27.541 & 24.050 & 1.004 \\
\hline$\%$ African American students & 30.240 & 20.236 & 1.004 \\
\hline \% Hispanic students & 9.319 & 10.061 & 1.003 \\
\hline$\%$ American Indian students & 31.570 & 30.224 & 0.998 \\
\hline$\%$ Using free or reduced lunch & 65.456 & 11.221 & 0.997 \\
\hline$\%$ Teachers with $4-10$ years of experiences & 28.753 & 9.232 & 0.991 \\
\hline$\%$ Teachers with $10+$ years of experiences & 51.225 & 14.073 & 1.003 \\
\hline$N$ & & & 3610 \\
\hline Model chi-square (df) & & & $336.03(28)^{* * *}$ \\
\hline
\end{tabular}

Note: Reference groups for indicator variables are shown in the parentheses.

${ }^{* * *} P<.001 ;{ }^{* *} P<.01 ;{ }^{*} P<.05$, two-tailed test.

or tense," and "I often feel fearful or anxious." This scale had a Cronbach's alpha reliability of 0.76 in this sample. The 12 item Aggression scale [70] assessed a variety of aggressive and noncompliant behaviors. Example items included "I get in many fights" and "I break rules at home, school, or elsewhere." The Cronbach's alpha reliability for this scale was 0.85 in this sample. The 5-item self-esteem scale was an adapted version of the Rosenberg Self-Esteem Scale [69], and example items included "I feel good about myself" and "I am able to do things as well as most other people." Five of the original items from Rosenberg were deleted for brevity on a long assessment, and items were worded to decrease confusion for a low-literacy middle school population. Cronbach's alpha reliability for this scale was 0.88 in the current sample. The seven-item School Satisfaction scale [67] measured each student's overall satisfaction with his/her school experience. Example items included "I enjoy going to this school" and "I am getting a good education at this school." The Cronbach's alpha reliability for this scale was 0.83 . Items from each of these scales used the same three-point Likert response options (Not Like Me, A Little Like Me, and A Lot Like Me).

2.4.3. Social Support. The five-item Friend Support scale [67] was measured on a three-point Likert scale (Not Like Me, A Little Like $\mathrm{Me}$, or A Lot Like Me). Example items included "I can count on my friends for support" and "I feel close to my friends." The Cronbach's alpha reliability for this scale was 0.89 for this sample.

The eight-item Teacher Support scale [67] measured students' perceptions of their teachers' supportive behavior. 
TABLE 2: Correlations among dependent variable indicators $(N=3597)$.

\begin{tabular}{|c|c|c|c|c|c|c|c|c|c|c|c|c|c|c|}
\hline & 1 & 2 & 3 & 4 & 5 & 6 & 7 & 8 & 9 & 10 & 11 & 12 & 13 & 14 \\
\hline (1) Victimized & 1.00 & & & & & & & & & & & & & \\
\hline (2) Insulted & 0.41 & 1.00 & & & & & & & & & & & & \\
\hline (3) Disrespected & 0.44 & 0.66 & 1.00 & & & & & & & & & & & \\
\hline (4) Ignored & 0.25 & 0.38 & 0.47 & 1.00 & & & & & & & & & & \\
\hline (5) Excluded & 0.30 & 0.38 & 0.43 & 0.42 & 1.00 & & & & & & & & & \\
\hline (6) Suspected of doing wrong & 0.23 & 0.33 & 0.40 & 0.40 & 0.39 & 1.00 & & & & & & & & \\
\hline (7) Treated unfairly & 0.39 & 0.51 & 0.62 & 0.50 & 0.53 & 0.45 & 1.00 & & & & & & & \\
\hline (8) Discouraged & 0.25 & 0.33 & 0.39 & 0.35 & 0.45 & 0.36 & 0.43 & 1.00 & & & & & & \\
\hline (9) Acted surprised when you did well & 0.15 & 0.20 & 0.27 & 0.29 & 0.28 & 0.33 & 0.29 & 0.34 & 1.00 & & & & & \\
\hline (10) Hassled & 0.39 & 0.47 & 0.51 & 0.37 & 0.42 & 0.36 & 0.53 & 0.42 & 0.27 & 1.00 & & & & \\
\hline (11) Yelled a racial slur & 0.27 & 0.37 & 0.41 & 0.33 & 0.38 & 0.35 & 0.44 & 0.41 & 0.27 & 0.43 & 1.00 & & & \\
\hline (12) Made fun of & 0.50 & 0.57 & 0.62 & 0.41 & 0.43 & 0.34 & 0.60 & 0.38 & 0.28 & 0.52 & 0.41 & 1.00 & & \\
\hline (13) Threatened to harm & 0.40 & 0.49 & 0.49 & 0.35 & 0.42 & 0.37 & 0.47 & 0.44 & 0.25 & 0.49 & 0.44 & 0.50 & 1.00 & \\
\hline (14) Pushed/shoved/hit & 0.37 & 0.44 & 0.49 & 0.37 & 0.41 & 0.39 & 0.47 & 0.36 & 0.28 & 0.43 & 0.39 & 0.53 & 0.54 & 1.00 \\
\hline
\end{tabular}

Example items included "My teachers care about me" and "My teachers give me a lot of encouragement." Each item was rated on a four-point Likert scale (Strongly Disagree, Disagree, Agree, or Strongly Agree), and the Cronbach's alpha reliability was 0.88 for this sample.

The five-item Parent Support scale [67] measured the frequency over the past 30 days that an adult in the child's home provided emotional support. Example items included "How often did the adults in your home tell you that you did a good job?" and "How often did the adults in your home make you feel special?" Each item was rated on a three-point Likert scale (Never, Once or Twice, or More than Twice), and the Cronbach's alpha reliability for this scale was 0.89 in this sample.

The five-item Neighborhood Support scale [67] measured the child's perception of the degree to which adults in the neighborhood are interested in and offer help to young people. Example items included "Adults in my neighborhood are interested in what young people in the neighborhood are doing" and "People in my neighborhood really help one another out." Each item was rated on a four-point Likert scale (Strongly Disagree, Disagree, Agree, or Strongly Agree), and the Cronbach's alpha reliability was 0.77 in this sample.

2.4.4. School Aggregated Characteristics. Publicly available administrative data was used to measure the following school characteristics. School size was a measure of the number of children attending each school. Student achievement was assessed as the percentage of students scoring at or above grade level on End of Grade (EOG) tests in reading and in math at the end of sixth grade. Teacher turnover rate was the percentage of teachers who left during the school year. Teacher quality was assessed as the percentage of teachers with advanced degrees. Racial and ethnic composition was measured by four variables: the percentage of White, African American, Hispanic, and American Indian students in a school. School poverty was assessed by the percentage of students receiving free or reduced lunches. Finally, teacher experience was measured by two variables: the percentage of teachers with four to ten years of teaching and the percentage of teachers with more than ten years of teaching experience; the percentage of teachers with zero to three years of experience was the reference group. All of these variables were administrative indicators not psychosocial scales, and, as such, they did not have internal consistency reliabilities.

2.5. Dependent Measures. The 13-item school hassles scale [67] measured the frequency with which students have endured peer harassment over the past 30 days. Example items included "Someone treated you in a disrespectful way," "Someone at school hassled you for no reason," and "Someone at school pushed, shoved, or hit you." The frequency of these events was measured on a three-point Likert scale (Never, Once or Twice, or More than Twice), and the Cronbach's alpha reliability was 0.90 in this sample.

Bullying victimization was measured with one item that asked each student if she or he had been the victim of bullying in the past twelve months. This was a dichotomous variable with 1 coded as "yes, victimized by a bully" and 0 for "no, not bullied in the past twelve months." Correlations among the dichotomous bullying victimization variable and 13 school hassles items are displayed in Table 2.

2.6. Data Analyses. By design, students coming from the same school may share common characteristics on an outcome variable compared to students from other schools, indicating the potential for clustering effects. The presence of clustering effects violates the independent-observation assumption embedded in a regression model and leads to an incorrect test about statistical significance of predictor variables. Using the intraclass correlation coefficient (ICC), we tested the clustering effects on both school hassles and bullying victimization variables. We first evaluated the ICC of the original school hassles scale (i.e., the ordinal variable) using the following equation [72]:

$$
\mathrm{ICC}=\frac{\sigma_{u}^{2}}{\sigma_{u}^{2}+\sigma_{e}^{2}},
$$

where $\sigma_{u}^{2}$ is the between-group variance and $\sigma_{e}^{2}$ is the within-group variance. Results showed that the ICC for the 
school hassles scale was 0.019 , indicating that $1.9 \%$ of the variation on the school hassles was between schools. We then evaluated the ICC of bullying victimization using the following equation [73]:

$$
\mathrm{ICC}=\frac{\psi}{\psi+\pi^{2} / 3}
$$

where $\psi$ is the variance of the random effect $u_{0 j}$ from the following multilevel logistic regression $\ln \left(P_{i j} /\left(1-P_{i j}\right)\right)=$ $\gamma_{00}+u_{0 j}, u_{0 j} \sim N(0, \psi)$ and $\pi=3.1416$. The estimated ICC for bullying victimization was 0.011 , indicating that $1.1 \%$ of variation in bullying victimization was between schools. Given the low ICC measures for both outcomes, we concluded that clustering effects were not present, and analysis based on the independent-observation assumption was valid.

The school hassles variable had a positively skewed distribution (results are available by request). Since linear models assume a normal distribution of the dependent variable, we did not analyze the variable in its original scale. Therefore, the current study employed an ordered logistic regression (Long, 1997). After rounding (i.e., recoding the values from 1 to 1.4 of $y$ into value 1 , the values from 1.5 to 2.4 of $y$ into value 2 , and the values from 2.5 to 3 of $y$ into value 3 ), the dependent variable $y$ had three ordinal levels, ranging from 1 to 3 . Ordered logistic regression assumes that each ordinal category is determined by the change of a latent continuous variable: with $k$ ordinal levels, the model assumes $k-1$ threshold or cutoff values of the continuous latent variable at which the observed category makes changes. For the current study, $k$ is 3 and the number of threshold values is 2 . The ordered logistic regression models the probability of having each of the three ordinal categories as a function of the independent variables and the two threshold values. Denoting school hassles as $y$, the independent variables as vector $x$, and the regression parameters as vector $\beta$, the probability of having an ordinal category may be expressed as

$$
\begin{aligned}
& \operatorname{Pr}(y=1 \mid x)=\frac{\exp \left(\tau_{1}-x \beta\right)}{1+\exp \left(\tau_{1}-x \beta\right)} \\
& \operatorname{Pr}(y=2 \mid x)=\frac{\exp \left(\tau_{2}-x \beta\right)}{1+\exp \left(\tau_{2}-x \beta\right)}-\frac{\exp \left(\tau_{1}-x \beta\right)}{1+\exp \left(\tau_{1}-x \beta\right)}, \\
& \operatorname{Pr}(y=3 \mid x)=1-\frac{\exp \left(\tau_{2}-x \beta\right)}{1+\exp \left(\tau_{2}-x \beta\right)}
\end{aligned}
$$

respectively, where $\tau_{1}$ and $\tau_{2}$ are the threshold values. In the above equation, each element in the estimated vector $\beta$ is a regression coefficient, and an exponent of the coefficient is an odds ratio. We employed the Stata ologit program (i.e., an estimator of maximum likelihood) to estimate the ordered logistic regression.

The bullying victimization variable was a dummy variable, coded 1 if the student reported being bullied and 0 otherwise, and, therefore, logistic regression was used. The model is expressed by the following equation:

$$
\ln =\left(\frac{P}{1-p}\right)=X \beta,
$$

where $P$ is the probability of $Y=1$ for the outcome variable, $X$ is the matrix of independent variables, and $\beta$ is the vector of regression coefficients showing effects of the independent variables. Taking the exponent of each element in estimating $\beta$ (i.e., $\exp (\widehat{\beta})$ ), we obtained the odds ratio for each independent variable, which is the final statistic presented in the findings section. To make the statistical inference more accurate, we further employed the Huber and White correction to obtain robust estimation of standard errors [74].

2.7. Cross-Level Interactions. Research hypotheses about a cross-level interaction may be represented by the following diagram depicting a multilevel proposition [73]:

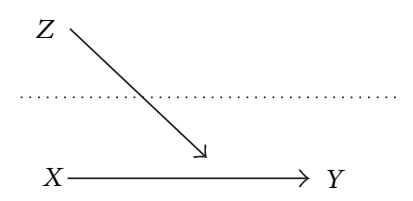

where $Y$ is the outcome variable, $X$ is a student-level independent variable, and $Z$ is a school-level independent variable. Based on the literature, we hypothesized that a schoollevel variable affects the relationship between a student-level variable and the outcome; that is, other things being equal, the impact of a student-level variable on the outcome varies by the level of school-level variable. Under this conceptualization, the school-level variable served as a moderator, and informed us of school settings that were important predictors to students' bullying experiences and school hassles.

We tested various cross-level interactions using individual and school characteristics. The student characteristics used in this analysis included anxiety, depression, and aggression. The school characteristics included teacher turnover rate, percentage of students at or above grade-level in reading and math, percentage of students using free or reduced lunch, and percentage of teachers with 10 or more years of experience. We began with an analysis including one crosslevel interaction in a model at a time. If multiple individual models showed statistically significant interactions, we then combined all significant interactions in one model.

2.8. Handling Missing Data. To handle missing data, we followed Allison [75] and employed listwise deletion. Consequently, the sample analyzed for the school hassles outcome is comprised of 3,602 students (i.e., $83.36 \%$ of the original sample), and the sample analyzed for the bullying victimization is comprised of 3,610 students (i.e., $83.54 \%$ of the original sample). A series of bivariate analyses were performed to discern differences on key demographic variables between the sample analyzed and the sample not analyzed. Results showed that the sample analyzed was slightly older (i.e., 0.15 
years older on average, $P<0.001)$, had a higher proportion of females (i.e., 11.5 percentage points higher, $P<0.001$ ), a lower proportion of students using free and reduced lunch (i.e., 9.5 percentage points lower, $P<0.001$ ), a lower proportion of African American students (i.e., 13.9 percentage points lower, $P<0.001)$, a higher proportion of American Indian students (i.e., 9.4 percentage points higher, $P<0.001$ ), and a slightly lower proportion of students with a mixed or other race (i.e., 2.8 percentage points lower, $P<0.05$ ) than the sample not analyzed. Based on these results, it is clear that the data was not "Missing At Random" (MAR), and, according to Allison, "[...] listwise deletion is the method that is most robust to violations of MAR [...]" [75, p. 6].

\section{Results}

Sample descriptive statistics and final model-estimated odds ratios of bullying victimization are shown in Table 1.

3.1. Correlates of Bullying Victimization. The overall model had an acceptable fit to the data, as reflected by the model chisquare of 336.03 (with 28 degrees of freedom, $P<0.001$ ). This model had a pseudo $R$-square of 0.0956 , indicating that $9.56 \%$ of the variation in bullying victimization can be attributed to the variables included in the model. Overall, there were 820 students (or $22.71 \%$ of the analyzed sample) who experienced bullying victimization. Among the 28 schools, the prevalence of bullying victimization in the past 12 months ranged from $11 \%$ to $38 \%$.

Younger students were more likely to experience bullying victimization $(P<0.001)$; every one-year increase in age decreased the probability of bullying victimization by $28 \%$. Hispanic students were less likely to experience bullying victimization than their White counterparts by $27.8 \%(P<$ 0.05 ); African American students were less likely to experience bullying victimization than their White counterparts by $41.5 \%(P<0.001)$.

Students reporting higher anxiety were more likely to experience bullying victimization $(P<0.001)$; every increase in anxiety increased the probability of bullying victimization by $51.4 \%$. Similarly, depressed students were more likely to experience bullying victimization $(P<0.001)$; every one-unit increase in depression increased the probability of bullying victimization by $76.4 \%$. Having higher school satisfaction decreased the likelihood of experiencing bullying victimization $(P<0.001)$; every one-unit increase in school satisfaction decreased the probability of bullying victimization by $51.7 \%$.

Social support from friends, but not from teachers, parents, or neighbors decreased the likelihood of experiencing bullying victimization $(P<0.01)$ : other things being equal, every one-unit increase in social support from friends was related to a $22.6 \%$ decrease in the probability of bullying victimization.

After a series of tests of cross-level interactions, we found no interactions between school characteristics and individual factors that were statistically significant in the model of bullying victimization.
3.2. School Hassles Model. Model-predicted probabilities are presented in Table 3. Overall, $61.47 \%$ of the analyzed sample reported low levels of school hassles and 2.61\% reported high levels of school hassles. The school hassles model has an acceptable fit to the data, as reflected by the chi-square of 846.21 (with 29 degrees of freedom) that was statistically significant at a 0.001 level. This model had a pseudo $R$-square of 0.1446 , indicating that $14.46 \%$ of the variation in school hassles can be attributed to the variables included in the model.

Results indicated that younger adolescents have a higher probability of reporting high school hassles than older adolescents (e.g., the probability of adolescents at age 11 reporting high school hassles was $3.72 \%$, compared to a probability of $1.40 \%$ for 16 year olds, $P<0.001)$. Males $(3.08 \%)$ have a significantly higher probability of reporting high school hassles than females $(2.25 \% ; P<0.001)$. Students who receive free or reduced price lunch (2.81\%) have a higher probability of reporting high school hassles than those not receiving free or reduced lunch $(2.26 \% ; P<0.01)$. In terms of race, White adolescents $(2.77 \%)$ had a significantly higher probability of reporting high school hassles than Hispanic adolescents $(2.21 \% ; P<0.05)$.

Students who reported low levels of school satisfaction (7.48\%) had a higher probability of reporting high school hassles than those who reported high school satisfaction (1.59\%; $P<0.001)$. Teacher, parent, friend, and neighborhood supports were not significantly related to school hassles.

Students who reported high levels of anxiety had a significantly higher probability of reporting high levels of school hassles $(6.75 \%)$ than students who reported low levels of school anxiety $(1.93 \% ; P<0.001)$. Students who reported high levels of depression (7.58\%) had a significantly higher probability of reporting high levels of school hassles than those who reported low levels of depression $(1.90 \%$; $P<$ 0.001).

Adolescents attending larger schools (i.e., those with 950 students; $3.17 \%$ ) had a higher probability of reporting high school hassles than those attending smaller schools (i.e., 150 students; $2.22 \%, P<0.05)$. Students attending schools that had a high percentage (i.e., $80 \%$ ) of students at or above grade level in reading (4.26\%) had a higher probability of reporting high school hassles than students attending schools with a low percentage (i.e., 40\%) of students at or above grade level in reading $(1.74 \% ; P<0.05)$. On the other hand, students attending schools that had a low percentage (i.e., $60 \%$ ) of students at or above grade level in math had a higher probability $(7.39 \%)$ of reporting high school hassles than students attending schools with a high percentage (i.e., 90\%) of students at or above grade level in math $(0.93 \% ; P<0.05)$. Adolescents attending schools with a low percentage (i.e., $10 \%)$ of teachers with advanced degrees had a significantly higher probability (3.11\%) of reporting high school hassles than students attending schools with a high percentage (i.e., $40 \%)$ of teachers with advanced degrees $(2.09 \% ; P<0.05)$. Students attending schools with a higher percentage (i.e., $80 \%$ ) of teachers with 10 or more years of experience had a significantly higher probability (3.22\%) of reporting high school hassles than students attending schools with a low 
TABLE 3: Model predicted probabilities of school hassles.

\begin{tabular}{|c|c|c|c|c|}
\hline \multirow{2}{*}{ Characteristic } & \multicolumn{4}{|c|}{ School hassles model } \\
\hline & Sig & Low & Medium & High \\
\hline All & & 0.6147 & 0.3593 & 0.0261 \\
\hline Age & $* * *$ & & & \\
\hline 11 & & 0.5250 & 0.4375 & 0.0372 \\
\hline 12 & & 0.5746 & 0.3947 & 0.0306 \\
\hline 13 & & 0.6225 & 0.3522 & 0.0252 \\
\hline 14 & & 0.6682 & 0.3111 & 0.0208 \\
\hline 15 & & 0.7108 & 0.2721 & 0.0171 \\
\hline 16 & & 0.7501 & 0.2359 & 0.0140 \\
\hline Gender & $* * *$ & & & \\
\hline Female & & 0.6493 & 0.3281 & 0.0225 \\
\hline Male & & 0.5738 & 0.3955 & 0.0308 \\
\hline Free/reduced price lunch & $* *$ & & & \\
\hline Yes & & 0.5967 & 0.3752 & 0.0281 \\
\hline No & & 0.6492 & 0.3282 & 0.0226 \\
\hline \multicolumn{5}{|l|}{ Race } \\
\hline $\begin{array}{l}\text { Non-Hispanic African } \\
\text { American }\end{array}$ & & 0.6156 & 0.3585 & 0.0260 \\
\hline Hispanic & * & 0.6538 & 0.3241 & 0.0221 \\
\hline Mixed/other & & 0.5974 & 0.3746 & 0.0280 \\
\hline Native American & & 0.6174 & 0.3568 & 0.0258 \\
\hline Non-Hispanic White & & 0.6000 & 0.3723 & 0.0277 \\
\hline School satisfaction & $* * *$ & & & \\
\hline Low & & 0.3458 & 0.5795 & 0.0748 \\
\hline Medium & & 0.5419 & 0.4232 & 0.0348 \\
\hline High & & 0.7259 & 0.2582 & 0.0159 \\
\hline \multicolumn{5}{|l|}{ Teacher support } \\
\hline Low & & 0.5852 & 0.3854 & 0.0294 \\
\hline Medium & & 0.6057 & 0.3673 & 0.0271 \\
\hline High & & 0.6258 & 0.3493 & 0.0249 \\
\hline \multicolumn{5}{|l|}{ Parent support } \\
\hline Low & & 0.6726 & 0.3070 & 0.0204 \\
\hline Medium & & 0.6386 & 0.3378 & 0.0236 \\
\hline High & & 0.6032 & 0.3695 & 0.0273 \\
\hline \multicolumn{5}{|l|}{ Friend support } \\
\hline Low & & 0.5670 & 0.4014 & 0.0316 \\
\hline Medium & & 0.5992 & 0.3730 & 0.0278 \\
\hline High & & 0.6305 & 0.3450 & 0.0244 \\
\hline \multicolumn{5}{|l|}{ Neighbor support } \\
\hline Low & & 0.6480 & 0.3293 & 0.0227 \\
\hline Medium & & 0.6235 & 0.3514 & 0.0251 \\
\hline High & & 0.5984 & 0.3738 & 0.0279 \\
\hline Anxiety & $* * *$ & & & \\
\hline Low & & 0.6848 & 0.2959 & 0.0193 \\
\hline Medium & & 0.5311 & 0.4326 & 0.0363 \\
\hline High & & 0.3712 & 0.5613 & 0.0675 \\
\hline
\end{tabular}

TABle 3: Continued.

\begin{tabular}{|c|c|c|c|c|}
\hline \multirow{2}{*}{ Characteristic } & \multicolumn{4}{|c|}{ School hassles model } \\
\hline & Sig & Low & Medium & High \\
\hline Depression & $* * *$ & & & \\
\hline Low & & 0.6876 & 0.2934 & 0.0190 \\
\hline Medium & & 0.5170 & 0.4446 & 0.0834 \\
\hline High & & 0.3424 & 0.5818 & 0.0758 \\
\hline \multicolumn{5}{|l|}{ Aggression } \\
\hline Low & & 0.4947 & 0.4635 & 0.0418 \\
\hline Medium & & 0.8074 & 0.1825 & 0.0101 \\
\hline High & & 0.9472 & 0.0504 & 0.0024 \\
\hline School size & * & & & \\
\hline 150 & & 0.6530 & 0.3248 & 0.0222 \\
\hline 550 & & 0.6102 & 0.3632 & 0.0266 \\
\hline 950 & & 0.5657 & 0.4025 & 0.0317 \\
\hline Grade level reading (\%) & * & & & \\
\hline 40 & & 0.7070 & 0.2756 & 0.0174 \\
\hline 60 & & 0.6034 & 0.3693 & 0.0273 \\
\hline 80 & & 0.4897 & 0.4677 & 0.0426 \\
\hline Grade level math (\%) & $* *$ & & & \\
\hline 60 & & 0.3486 & 0.5775 & 0.0739 \\
\hline 75 & & 0.6095 & 0.3639 & 0.0266 \\
\hline 90 & & 0.8199 & 0.1708 & 0.0093 \\
\hline \multicolumn{5}{|l|}{ Teacher turnover (\%) } \\
\hline 0 & & 0.6174 & 0.3568 & 0.0258 \\
\hline 25 & & 0.6114 & 0.3622 & 0.0264 \\
\hline 50 & & 0.6053 & 0.3676 & 0.0271 \\
\hline Teachers w/advanced degrees (\%) & * & & & \\
\hline 10 & & 0.5707 & 0.3981 & 0.0311 \\
\hline 25 & & 0.6197 & 0.3548 & 0.0255 \\
\hline 40 & & 0.6663 & 0.3128 & 0.0209 \\
\hline \multicolumn{5}{|l|}{$\%$ of White students } \\
\hline 1 & & 0.6341 & 0.3418 & 0.0241 \\
\hline 40 & & 0.6054 & 0.3675 & 0.0271 \\
\hline 80 & & 0.5752 & 0.3942 & 0.0306 \\
\hline \multicolumn{5}{|l|}{$\%$ of African American students } \\
\hline 1 & & 0.6069 & 0.3662 & 0.0269 \\
\hline 40 & & 0.6173 & 0.3569 & 0.0258 \\
\hline 80 & & 0.6278 & 0.3475 & 0.0247 \\
\hline \multicolumn{5}{|l|}{$\%$ of Hispanic students } \\
\hline 1 & & 0.6046 & 0.3682 & 0.0272 \\
\hline 25 & & 0.6335 & 0.3424 & 0.0241 \\
\hline 50 & & 0.6627 & 0.3161 & 0.0213 \\
\hline \multicolumn{5}{|l|}{$\%$ of native American students } \\
\hline 0 & & 0.6181 & 0.3562 & 0.0257 \\
\hline 50 & & 0.6127 & 0.3610 & 0.0263 \\
\hline 100 & & 0.6073 & 0.3659 & 0.0269 \\
\hline
\end{tabular}


TABLE 3: Continued.

\begin{tabular}{|c|c|c|c|c|}
\hline \multirow{2}{*}{ Characteristic } & \multicolumn{4}{|c|}{ School hassles model } \\
\hline & Sig & Low & Medium & High \\
\hline \multicolumn{5}{|l|}{$\begin{array}{l}\% \text { students receiving free/reduced } \\
\text { lunch }\end{array}$} \\
\hline 10 & & 0.6063 & 0.3667 & 0.0270 \\
\hline 45 & & 0.6108 & 0.3627 & 0.0265 \\
\hline 80 & & 0.6153 & 0.3587 & 0.0260 \\
\hline \multicolumn{5}{|l|}{$\begin{array}{l}4-10 \text { years of teacher experience } \\
(\%)\end{array}$} \\
\hline 10 & & 0.6362 & 0.3399 & 0.0238 \\
\hline 30 & & 0.6132 & 0.3605 & 0.0262 \\
\hline 50 & & 0.5897 & 0.3814 & 0.0289 \\
\hline $10+$ years of experience $(\%)$ & $*$ & & & \\
\hline 30 & & 0.6518 & 0.3259 & 0.0223 \\
\hline 55 & & 0.6079 & 0.3653 & 0.0268 \\
\hline 80 & & 0.5622 & 0.4056 & 0.0322 \\
\hline Grade level math $\times$ aggression & $*$ & & & \\
\hline 55 & & 0.8473 & 0.1450 & 0.0076 \\
\hline 105 & & 0.5841 & 0.3864 & 0.0295 \\
\hline 265 & & 0.0170 & 0.2711 & 0.7119 \\
\hline$N$ & & & 35 & \\
\hline Model chi-square (df) & & & 846.21( & $29)^{* * *}$ \\
\hline
\end{tabular}

Note: $P<.05^{*} ; P<.01^{* *} ; P<.001^{* * *}$, two-tailed test.

percentage (i.e., $30 \%$ ) of teachers with 10 or more years of experience $(2.23 \% ; P<0.05)$.

After testing a series of cross-level interactions, we found only one interaction (i.e., the percentage of students at or above grade level in math by student's aggression) that was statistically significant. Due to the complexity of interpreting model-predicted probabilities of interaction terms, the results of aggression by students at or above grade level in math interaction are displayed graphically in Figure 1. For adolescents reporting high levels of aggression (i.e., aggression $=3$ ), as the percentage of students at or above grade level in math increases, the probability of reporting high school hassles also increases. However, the opposite trend is true for students reporting medium and low levels of aggression (i.e., aggression $=2$ or 1 ). For these students, as the percentage of students at or above grade level in math increases, the probability of reporting high school hassles decreases.

\section{Discussion}

This study contributed to our knowledge of school hassles and bullying victimization by illuminating individual and school environment risk factors in a large sample of rural youth. Considering the dearth of extant information on rural youth, it is noteworthy that these youth experienced school hassles and bullying at rates comparable to urban and suburban youth. Overall, $23 \%$ of rural youth reported being bullied in the past twelve months, with a range of $11 \%$ in the least

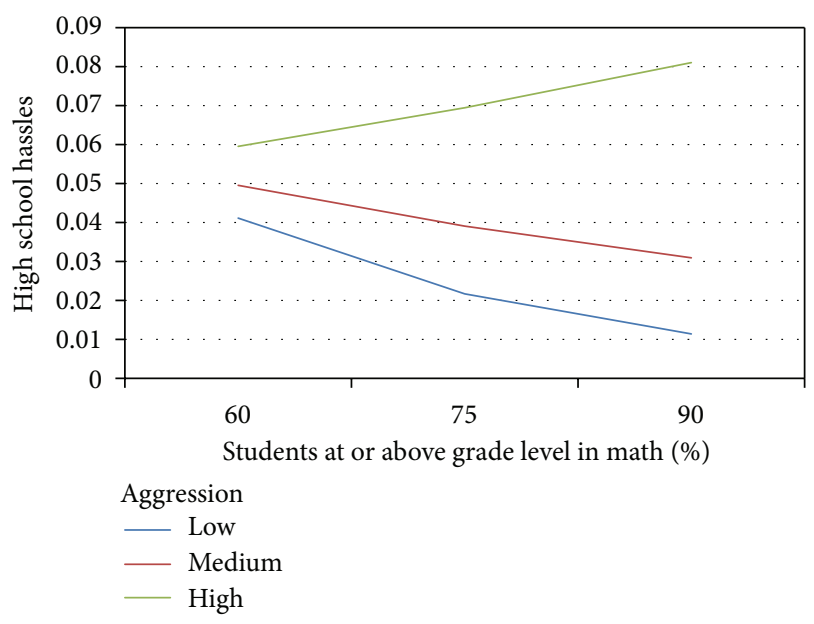

FIGURE 1: Model-predicted probability of reporting a high level of school hassles.

violent school to $38 \%$ in the most violent school. This overall prevalence rate is higher than a previous study on extreme victimization (10\%) [76] and a national survey that included both bullies and victims (13.6\%) [4]. This underscores the need to more fully understand bullying dynamics in rural areas. The prevalence of bullying in the rural areas we assessed was not only higher than the national rate, it was over $25 \%$ in nine out of the 25 schools assessed. Further, this rate is only for victimization, and adding the bullies who perpetrated the aggression would potentially double the rate of children involved in the bullying dynamic.

Our model identified important demographic risk factors for bullying victimization and experiencing school hassles. Reports of victimization and school hassles decreased with age and were more common for males than females. This finding was in line with previous research that found bullying to be most common in lower grades [3]. The elevated risk for males in these rural areas contrasted with higher rates for females in national data [77] but were consistent with other research showing that males were bullying perpetrators and victims more often than females $[3,36]$. This gender effect was more relevant to reported school hassles than bullying. These school hassles centered on physical aggression, harassment, and overt disrespectful encounters more than subtle social ostracism that females reported when they were victimized [78]. Another possible explanation for this gender difference is the fact that some rural communities in the United States follow prescribed gender roles, where men are supposed to be masculine and dominant and women are expected to be subservient [79]. It is well documented that male victims of bullying often do not fit this "masculine ideal", and, it is possible that, in this rural setting, they are therefore at an increased risk for bullying victimization as compared to their urban counterparts.

African American and Hispanic students reported significantly less victimization compared to their Caucasian classmates. American Indian students also reported lower rates, but the difference was not statistically significant relative to Caucasian students. These racial differences placing 
Caucasian students at higher risk were also found in previous studies $[60,77]$ but have garnered little discussion in the research literature. It appears that children are victimized for a variety of reasons (e.g., lacking power and relationships, being insecure, physically weak or different), but coming from a racial or ethnic minority group may not be a strong rationale for being bullied. In this sample, there were almost equal percentages of the various racial groups. This suggests that minority children are not isolated and the high number of same minority peers may provide safety from being singled out or segregated. It is also possible that Hispanic and African American victims labeled their victimization experiences as discrimination rather than bullying. This is not clear without further qualitative investigation. Alternately, bullies may have understood that race was an exceptionally sensitive topic that may quickly bring remediation (e.g., bullying by race can be translated into a hate crime with severe penalties). It then becomes safer to victimize a weak Caucasian child instead of a minority student, especially in the diverse environment in this study. All of these explanations warrant future research.

Socioeconomically disadvantaged students who received free or reduced school lunches reported more school hassles, but were not at significantly higher risk for bullying victimization. Given that the current measure of school hassles included many behaviors identified in the literature as bullying, it is interesting that this discrepancy exists. A possible explanation for this discrepancy is a difference between students' definition of bullying and adults/researchers' definition $[7,80]$. These students endorsed suffering from school hassles but may not have labeled these experiences as bullying. This is a mixed finding that requires additional research to hypothesize a substantive interpretation of this relationship.

In partial support of Hypothesis 3 and in line with previous research [35], students who reported high levels of anxiety and depression were significantly more likely to experience bullying victimization and school hassles. In light of the symptoms associated with anxiety and depression (e.g., excessive worry, constant sadness, irritability, reduced interest in activities) [81], it is possible that these adolescents may stand out from their peers and be targeted by bullies. Another possibility is that the increased levels of anxiety and depression may be a consequence of the bullying victimization. Cross-sectional data will not support assertions about causality; however, it is likely that there is a strong feedback loop between victimization and mental health symptoms. This finding points to the importance of teachers paying close attention both to students who are bullied and to students who appear depressed or anxious. Teachers should be cognizant of sudden or gradual changes in mood as this could be indicative of victimization. Contrary to hypothesis 3 , aggression and self-esteem were not significantly related to bullying victimization or school hassles.

As expected, few school level characteristics were directly associated with bullying and school hassles. Current findings mirror past literature, suggesting higher rates of hassles in larger schools [54]. It is likely that in larger schools teachers are less able to monitor students' behaviors, leading to increased rates of problem behaviors. Teacher characteristics were also important. Schools with more teachers who have advanced degrees had a lower probability for their students to experience school hassles; however, schools with more teachers who had taught for more than 10 years tended to have a higher probability for their students to experience school hassles. Together, these effects suggest that students' perceptions of school hassles may be decreased by having knowledgeable teachers who are well prepared in their fields but who have not taught long enough to be "burned out." Perhaps teachers who have taught more than 10 years have continually attempted to interrupt students hassling one another without success and have therefore given up trying to intervene. A potential point of intervention could be to provide teachers with effective behavior management and intervention strategies. Contrary to our expectations, there was only one significant cross-level interaction: the interaction of percentage of students at or above grade level in math and aggression on school hassles. For adolescents who reported high levels of aggression, as percentage of students at or above grade level in math increased, the probability of reporting high school hassles also increased. High levels of aggression often coincide with low academic success [82]. It is possible that, in this sample, students reporting high levels of aggression were also unsuccessful academically and therefore did not fit in with their high achieving peers making them targets for peer ridicule.

In line with hypothesis 1, microsystem factors were more important predictors than school level factors, confirming previous reports [48]. The protective effect of school satisfaction was one of our most noteworthy effects related to both bullying and school hassles. Enhancing school satisfaction is an appropriate target for prevention scientists who seek to reduce bullying. In terms of social support, our hypothesis was partially supported. Peer support was the only significant source of support that predicted lower bullying victimization. This finding points to the importance that the peer group has for adolescents, perhaps suggesting the utility of an intervention focused on peer mediation and strengthening the quality of peer relationships. It is possible that parent, teacher, and neighbor supports were not significantly associated with school hassles and bullying victimization because these adult figures might not be aware that bullying and school hassles are occurring. Peers might be able to intervene and support victims more easily than these adults as peers are more likely to witness the bullying and school hassles than parents, teachers, and neighbors.

\section{Limitations}

A significant limitation in this study was the way that bullying was measured. A dichotomous variable does not allow for an evaluation of frequency of bullying incidents, so therefore a child who has been bullied once or twice is treated synonymously with a child who was chronically bullied. In addition, the bullying question does not define bullying, leaving interpretation up to the reader, which could be problematic based on the known discrepancy between students' and researchers' definitions of bullying [7, 80]. However, other researchers [83-85] have used dichotomous bullying 
variables in conjunction with other scales. The present study employed a similar approach and used a dichotomous bullying variable in conjunction with the school hassles scale. As seen in Table 2, correlations between bullying victimization and items from the school hassles scale are statistically significant and substantively important. Thus, although the bullying variable on its own is flawed, we considered the two measures complimentary and informative. While it would have been preferable to have a more comprehensive measure of bullying, this was not feasible in the current study due to time constraints in filling out the survey.

The generalizability of the current study is limited as participants were middle school students in two low-income, ethnically diverse, rural counties. Caution is warranted when applying these results to other groups of youth. Additionally, students completed the surveys at school, in the presence of other students and it is possible that they did not answer truthfully or were influenced by the presence of their peers. However, researchers made the setting as private as possible and reinforced the confidential nature of the surveys.

\section{Conclusion}

This study assessed correlates of bullying victimization and school hassles in a large sample of rural, low-income youth. In general, these rural youth suffered from both bullying victimization and school hassles at a surprisingly high rate. Given the well-documented consequences of bullying victimization, these findings point to the importance of prevention and intervention programming in rural schools, especially for male adolescents and for students coping with anxiety and depression. Additional research is needed to fully understand the influence of socioeconomic status on bullying victimization and school hassles. Due to the lack of significant findings, additional research on school-level variables is also warranted. Overall, this study contributes to the literature on risk factors for rural youth and augments the existing literature on bullying victimization.

\section{Acknowledgment}

This study was funded through a cooperative agreement with the United States Centers for Disease Control and Prevention's National Center for Injury Prevention and Control (5 U01 CE001948).

\section{References}

[1] A. V. Beale, "Bullybusters: using drama to empower students to take a stand against bullying behavior," Professional School Counseling, vol. 4, pp. 300-306, 2001.

[2] National School Safety Center, School Bullying and Victimization NSSC Resource Paper, National School Safety Center, Malibu, India, 1995.

[3] T. R. Nansel, M. Overpeck, R. S. Pilla, W. J. Ruan, B. SimonsMorton, and P. Scheidt, "Bullying behaviors among US youth: prevalence and association with psychosocial adjustment," Journal of the American Medical Association, vol. 285, no. 16, pp. 2094-2100, 2001.
[4] J. Wang, R. J. Iannotti, and T. R. Nansel, "School bullying among adolescents in the United States: physical, verbal, relational, and cyber," Journal of Adolescent Health, vol. 45, no. 4, pp. 368-375, 2009.

[5] G. Glew, F. Rivara, and C. Feudtner, "Bullying: children hurting children," Pediatrics in Review, vol. 21, no. 6, pp. 183-189, 2000.

[6] A. Frisén, K. Holmqvist, and D. Oscarsson, "13-year-olds" perception of bullying: definitions, reasons for victimisation and experience of adults' response," Educational Studies, vol. 34, no. 2, pp. 105-117, 2008.

[7] S. Guerin and E. Hennessy, "Pupils' definitions of bullying," European Journal of Psychology of Education, vol. 17, no. 3, pp. 249-261, 2002.

[8] A. D. Pellegrini, M. Bartini, and F. Brooks, "School bullies, victims, and aggressive victims: factors relating to group affiliation and victimization in early adolescence," Journal of Educational Psychology, vol. 91, no. 2, pp. 216-224, 1999.

[9] W. B. Roberts, "The bully as victim," Professional School Counseling, vol. 4, pp. 148-156, 2000.

[10] B. E. McNamara and F. J. McNamara, Keys to Dealing with Bullies, Barron's, Hauppauge, NY, USA, 1997.

[11] S. Atav and G. A. Spencer, "Health risk behaviors among adolescents attending rural, suburban, and urban schools: a comparative study," Family and Community Health, vol. 25, no. 2, pp. 53-64, 2002.

[12] G. E. Barboza, L. B. Schiamberg, J. Oehmke, S. J. Korzeniewski, L. A. Post, and C. G. Heraux, "Individual characteristics and the multiple contexts of adolescent bullying: an ecological perspective," Journal of Youth and Adolescence, vol. 38, no. 1, pp. 101-121, 2009.

[13] S. M. Swearer and B. Doll, "Bullying in schools: an ecological framework," Journal of Emotional Abuse, vol. 2, no. 2-3, pp. 723, 2001.

[14] S. M. Swearer, D. L. Espelage, T. Vaillancourt, and S. Hymel, "What can be done about school bullying? linking research to educational practice," Educational Researcher, vol. 39, no. 1, pp. $38-47,2010$.

[15] U. Bronfrenbrenner, "Ecological models of human development," in International Encyclopedia of Education, M. Gauvain and M. Cole, Eds., vol. 3, pp. 37-43, Elsevier, Oxford, UK, 2nd edition, 1994, Reprinted in Readings on the Development of Children.

[16] U. Bronfrenbrenner, "Toward an experimental ecology of human development," The American Psychologist, vol. 32, no. 7, pp. 513-531, 1977.

[17] C. McKown, "Applying ecological theory to advance the science and practice of school-based prejudice reduction interventions," Educational Psychologist, vol. 40, no. 3, pp. 177-189, 2005.

[18] K. T. Carlson, "Poverty and youth violence exposure: experiences in rural communities," Children and Schools, vol. 28, no. 2, pp. 87-96, 2006.

[19] J. Dawkins and P. Hill, "Bullying: another form of abuse," in Recent Advances in Pediatrics, T. J. David, Ed., pp. 103-122, Livingston, Edinburgh, UK, 1995.

[20] K. M. Boydell, R. Pong, T. Volpe, K. Tilleczek, E. Wilson, and S. Lemieux, "Family perspectives on pathways to mental health care for children and youth in rural communities," The Journal of Rural Health, vol. 22, no. 2, pp. 182-188, 2006. 
[21] R. Spoth, C. Goldberg, T. Neppl, L. Trudeau, and S. RamisettyMikler, "Rural-urban differences in the distribution of parentreported risk factors for substance use among young adolescents," Journal of Substance Abuse, vol. 13, no. 4, pp. 609-623, 2001.

[22] D. Witherspoon and S. Ennett, "Stability and change in rural youths' educational outcomes through the middle and high school years," Journal of Youth and Adolescence, vol. 40, no. 9, pp. 1077-1090, 2011.

[23] R. L. Dukes and J. A. Stein, "Gender and gang membership: a contrast of rural and urban youth on attitudes and behavior," Youth \& Society, vol. 34, no. 4, pp. 415-440, 2003.

[24] F. J. Elgar, J. Knight, G. J. Worrall, and G. Sherman, "Behavioural and substance use problems in rural and urban delinquent youths," Canadian Journal of Psychiatry, vol. 48, no. 9, pp. 633636, 2003.

[25] J. L. Grama, "Women forgotten: difficulties faced by rural victims of domestic violence," American Journal of Family Law, vol. 14, pp. 173-189, 2000.

[26] U.S. Department of Justice, Office for Victims of Crime, Office of Justice Programs, "Rural victim assistance: a victim/witness guide for rural prosecutors (NCJ No. 211106)," 2001, http://www .ovc.gov/publications/infores/rural_victim_assistance/pfv.html.

[27] V. Robbins, N. Dollard, B. J. Armstrong, K. Kutash, and K. S. Vergon, "Mental health needs of poor suburban and ruralchildren and their families," Journal of Loss and Trauma, vol. 13, no. 2-3, pp. 94-122, 2008.

[28] G. Gini, "Associations between bullying behaviour, psychosomatic complaints, emotional and behavioural problems," Journal of Paediatrics and Child Health, vol. 44, no. 9, pp. 492497, 2008.

[29] N. G. Guerra, K. R. Williams, and S. Sadek, "Understanding bullying and victimization during childhood and adolescence: a mixed methods study," Child Development, vol. 82, no. 1, pp. 295-310, 2011.

[30] M. O'Moore and C. Kirkham, "Self-esteem and its relationship to bullying behaviour," Aggressive Behavior, vol. 27, no. 5, pp. 269-283, 2001.

[31] K. Kumpulainen, E. Räsänen, I. Henttonen et al., "Bullying and psychiatric symptoms among elementary school-age children," Child Abuse and Neglect, vol. 22, no. 7, pp. 705-717, 1998.

[32] E. Menesini, M. Modena, and F. Tani, "Bullying and victimization in adolescence: concurrent and stable roles and psychological health symptoms," Journal of Genetic Psychology, vol. 170, no. 2, pp. 115-133, 2009.

[33] G. Salmon, A. James, E. L. Cassidy, and M. A. Javaloyes, "Bullying a review: presentations to an adolescent psychiatric service and within a school for emotionally and behaviourally disturbed children," Clinical Child Psychology and Psychiatry, vol. 5, no. 4, pp. 563-579, 2000.

[34] H. Sweeting, R. Young, P. West, and G. Der, "Peer victimization and depression in early-mid adolescence: a longitudinal study," British Journal of Educational Psychology, vol. 76, no. 3, pp. 577594, 2006.

[35] R. Kaltiala-Heino, M. Rimpelä, F. Rantanen, and A. Rimpelä, "Bullying at school-an indicator of adolescents at risk for mental disorders," Journal of Adolescence, vol. 23, no. 6, pp. 661$674,2000$.

[36] D. Seals and J. Young, "Bullying and victimization: prevalence and relationship to gender, grade level, ethnicity, self-esteem, and depression," Adolescence, vol. 38, no. 152, pp. 735-747, 2003.
[37] C. Salmivalli and E. Nieminen, "Proactive and reactive aggression among school bullies, victims, and bully-victims," Aggressive Behavior, vol. 28, no. 1, pp. 30-44, 2002.

[38] B. H. Gottlieb, "Social support and the study of personal relationships," Journal of Social and Personal Relationships, vol. 2, no. 3, pp. 351-175, 1985.

[39] P. D. Flaspohler, J. L. Elfstrom, K. L. Vanderzee, H. E. Sink, and Z. Birchmeier, "Stand by me: the effects of peer and teacher support in mitigating the impact of bullying on quality of life," Psychology in the Schools, vol. 46, no. 7, pp. 636-649, 2009.

[40] M. J. Furlong, A. Chung, M. Bates, and R. L. Morrison, "Who are the victims of school violence? A comparison of student nonvictims and multi-victims," Education \& Treatment of Children, vol. 18, no. 3, pp. 282-298, 1995.

[41] M. K. Demaray and C. K. Malecki, "Perceptions of the frequency and importance of social support by students classified as victims, bullies, and bully/victims in an urban middle school," School Psychology Review, vol. 32, no. 3, pp. 471-489, 2003.

[42] M. K. Holt and D. L. Espelage, "Perceived social support among bullies, victims, and bully-victims," Journal of Youth and Adolescence, vol. 36, no. 8, pp. 984-994, 2007.

[43] D. Foltz-Gray, "The bully trap: young tormentors and their victims find ways out of anger and isolation," Teaching Tolerance, vol. 5, pp. 18-23, 1996.

[44] R. Hazler, J. Hoover, and R. Oliver, "What children say about bullying," The Executive Educator, vol. 14, pp. 20-22, 1992.

[45] S. You, M. J. Furlong, E. Felix, J. D. Sharkey, D. Tanigawa, and J. G. Green, "Relations among school connectedness, hope, life satisfaction, and bully victimization," Psychology in the Schools, vol. 45, no. 5, pp. 446-460, 2008.

[46] C. N. Dulmus, M. T. Theriot, K. M. Sowers, and J. A. Blackburn, "Student reports of peer bullying victimization in a rural school," Stress, Trauma and Crisis, vol. 7, no. 1, pp. 1-16, 2004.

[47] A. L. Spriggs, R. J. Iannotti, T. R. Nansel, and D. L. Haynie, "Adolescent bullying involvement and perceived family, peer and school relations: commonalities and differences across race/ethnicity," Journal of Adolescent Health, vol. 41, no. 3, pp. 283-293, 2007.

[48] M. Khoury-Kassabri, "Student victimization by peers in elementary schools: individual, teacher-class, and school-level predictors," Child Abuse and Neglect, vol. 35, no. 4, pp. 273-282, 2011.

[49] C. Lleras, "Hostile school climates: explaining differential risk of student exposure to disruptive learning environments in high school," Journal of School Violence, vol. 7, no. 3, pp. 105-135, 2008.

[50] J. S. Ferris and E. G. West, "Economies of scale, school violence and the optimal size of schools," Applied Economics, vol. 36, no. 15, pp. 1677-1684, 2004.

[51] G. Chen, "Communities, students, schools, and school crime: a confirmatory study of crime in U.S. high schools," Urban Education, vol. 43, no. 3, pp. 301-318, 2008.

[52] H. M. Walker and F. M. Gresham, "Making schools safer and violence free," Intervention in School and Clinic, vol. 32, no. 4, pp. 199-204, 1997.

[53] R. Crosnoe, M. K. Johnson, and G. H. Elder Jr., "School size and the interpersonal side of education: an examination of race/ ethnicity and organizational context," Social Science Quarterly, vol. 85, no. 5, pp. 1259-1274, 2004.

[54] L. Bowes, L. Arseneault, B. Maughan, A. Taylor, A. Caspi, and T. E. Moffitt, "School, neighborhood, and family factors are 
associated with children's bullying involvement: a nationally representative longitudinal study," Journal of the American Academy of Child and Adolescent Psychiatry, vol. 48, no. 5, pp. 545-553, 2009.

[55] X. Ma, "Bullying in middle school: individual and school characteristics of victims and offenders," School Effectiveness and School Improvement, vol. 13, no. 1, pp. 63-89, 2002.

[56] H. Wei, J. H. Williams, J. Chen, and H. Chang, "The effects of individual characteristics, teacher practice, and school organizational factors on students' bullying: a multilevel analysis of public middle schools in Taiwan," Children and Youth Services Review, vol. 32, no. 1, pp. 137-143, 2010.

[57] S. L. Wynne and H. Joo, "Predictors of school victimization: individual, familial, and school factors," Crime and Delinquency, vol. 57, no. 3, pp. 458-488, 2011.

[58] J. G. Green, E. C. Dunn, R. M. Johnson, and B. E. Molnar, "A multilevel investigation of the association between school context and adolescent nonphysical bullying," Journal of School Violence, vol. 10, no. 2, pp. 133-149, 2011.

[59] J. Barnes, J. Belsky, K. A. Broomfield, and E. Melhuish, "Neighbourhood deprivation, school disorder and academic achievement in primary schools in deprived communities in England," International Journal of Behavioral Development, vol. 30, no. 2, pp. 127-136, 2006.

[60] C. P. Bradshaw, A. L. Sawyer, and L. M. O’Brennan, "A social disorganization perspective on bullying-related attitudes and behaviors: the influence of school context," American Journal of Community Psychology, vol. 43, no. 3-4, pp. 204-220, 2009.

[61] U.S. Census Bureau, "State and county quick facts," 2011, http:// quickfacts.census.gov/qfd/states/37/37155.html.

[62] E. J. Heisler, "The U.S. infant mortality rate: international comparisons, underlying factors, federal programs," Congressional Research Service, 2012, http://www.fas.org/sgp/crs/misc/ R41378.pdf.

[63] North Carolina Department of Health and Human Services State Center for Health Statistics, "2011 North Carolina infant mortality report, Table 1," 2012, http://www. schs.state.nc.us/SCHS/deaths/ims/2011/2011rpt.html.

[64] A. M. Minino, S. L. Murphy, J. Xu, and K. D. Kochanek, "National vital statics reports, deaths: final data for 2008," National Center for Health Statistics, vol. 59, no. 10, 2011.

[65] Bureau of Labor Statistics, "Local area unemployment statistics map," 2012, http://www.bls.gov/lau/.

[66] B. A. Lee, J. Iceland, and G. Sharp, "Racial and ethnic diversity goes local: charting change in American communities over three decades," 2012, http://www.s4.brown.edu/us2010/Data/ Report/report08292012.pdf.

[67] G. L. Bowen and J. M. Richman, The School Success Profile, The University of North Carolina at Chapel Hill, Chapel Hill, NC, USA, 2008.

[68] G. L. Bowen, R. S. Rose, and N. K. Bowen, The Reliability and Validity of the School Success Profile, Xlibris, Philadelphia, $\mathrm{Pa}$, USA, 2005.

[69] M. Rosenberg, Society and the Adolescent Self-Image, Princeton University Press, Princeton, NJ, USA, 1965.

[70] T. M. Achenbach and L. A. Rescorla, Manual for ASEBA SchoolAge Forms and Profiles, University of Vermont, Research Center for Children, Youth \& Families, Burlington, Vt, USA, 2001.

[71] M. Y. Ivanova, T. M. Achenbach, L. A. Rescorla et al., "The generalizability of the youth self-report syndrome structure in 23 societies," Journal of Consulting and Clinical Psychology, vol. 75, no. 5, pp. 729-738, 2007.
[72] S. W. Raudenbush and A. S. Bryk, Hierarchical Linear Models: Applications and Data Analysis Methods, Sage Publications, Thousand Oaks, Calif, USA, 2nd edition, 2002.

[73] T. A. B. Snijders and R. J. Bosker, Multilevel Analysis: An Introduction to Basic and Advanced Multilevel Modeling, Sage Publications, Thousand Oaks, Calif, USA, 1999.

[74] Stata Corporation, Stata User's Guide: Release 10, Stata Corp, LP, College Station, Tex, USA, 2007.

[75] P. Allison, Missing Data, Sage Publications, Thousand Oaks, Calif, USA, 2002.

[76] D. G. Perry, S. J. Kusel, and L. C. Perry, "Victims of peer aggression,” Developmental Psychology, vol. 24, no. 6, pp. 807-814, 1988.

[77] Centers for Disease Control and Prevention, "1991-2009 High School Youth Risk Behavior Survey data," 2012, http://apps.nccd.cdc.gov/youthonline.

[78] N. R. Crick and D. A. Nelson, "Relational and physical victimization within friendships: nobody told me there'd be friends like these," Journal of Abnormal Child Psychology, vol. 30, no. 6, pp. 599-607, 2002.

[79] J. Little and R. Panelli, "Gender research in rural geography," Gender, Place and Culture, vol. 10, no. 3, pp. 281-289, 2003.

[80] C. P. Monks and P. K. Smith, "Definitions of bullying: age differences in understanding of the term, and the role of experience," British Journal of Developmental Psychology, vol. 24, no. 4, pp. 801-821, 2006.

[81] American Psychiatric Association, Diagnostic and Stastical Manual of Mental Disorders, American Psychiatric Association, Washington, DC, USA, 4th edition, 2000.

[82] S. P. Hinshaw, "Academic underachievement, attention deficits, and aggression: comorbidity and implications for intervention," Journal of Consulting and Clinical Psychology, vol. 60, no. 6, pp. 893-903, 1992.

[83] C. Salmivalli, A. Kaukiainen, and M. Voeten, "Anti-bullying intervention: implementation and outcome," British Journal of Educational Psychology, vol. 75, no. 3, pp. 465-487, 2005.

[84] J. W. Patchin and S. Hinduja, "Traditional and nontraditional bullying among youth: a test of general strain theory," Youth \& Society, vol. 43, no. 2, pp. 727-751, 2011.

[85] C. Salmivalli, A. Kaukiainen, M. Voeten, and M. Sinisammal, "Targeting the group as a whole: the Finish ant-bullying intervention," in Bullying in Schools: How Successful Can Interventions Be? P. K. Smith, D. Pepler, and K. Rigby, Eds., pp. 251274, Cambridge University Press, New York, NY, USA, 2004. 

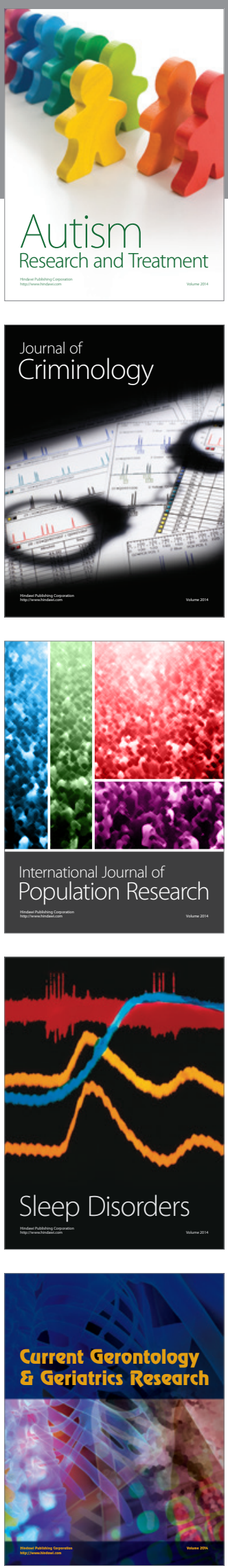
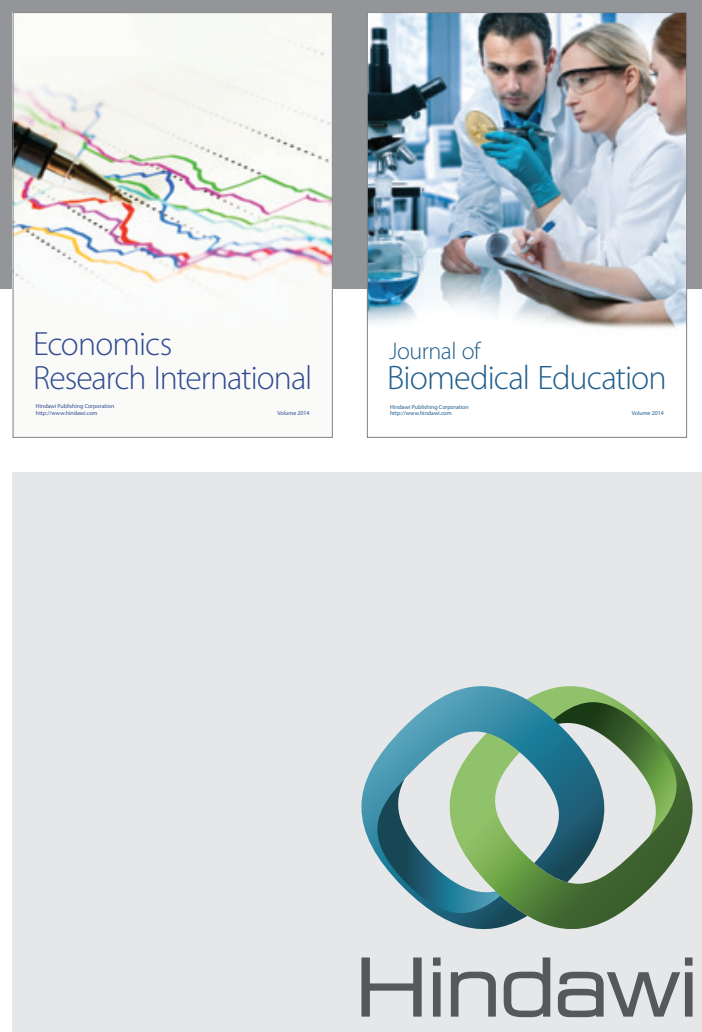

Submit your manuscripts at

http://www.hindawi.com
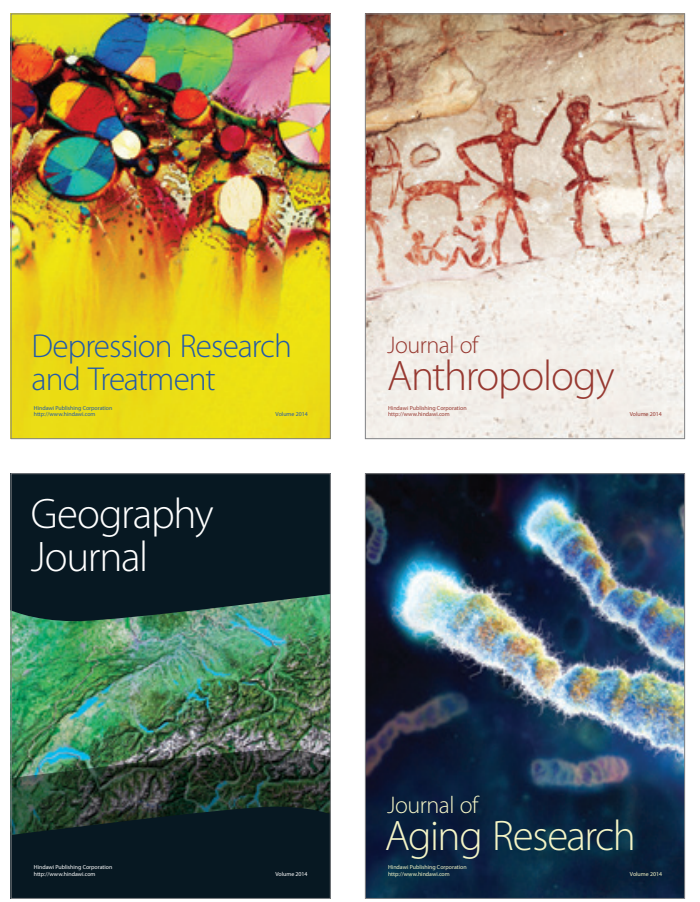
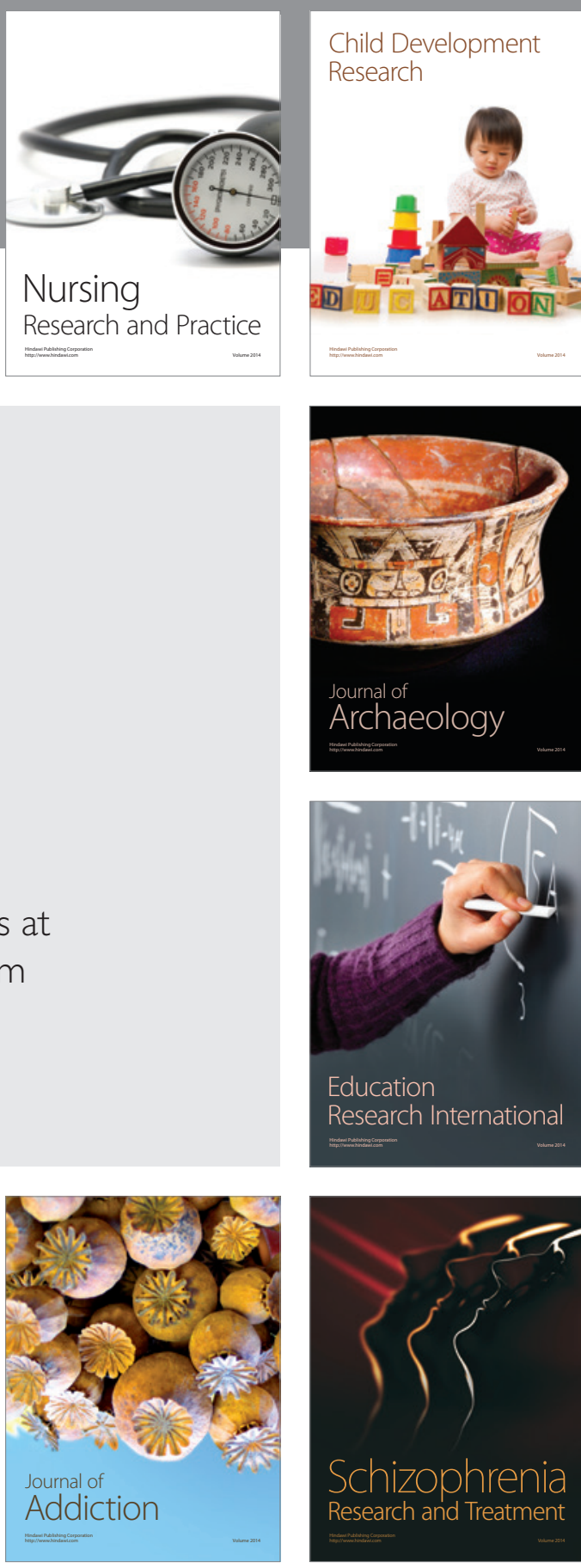

(D)
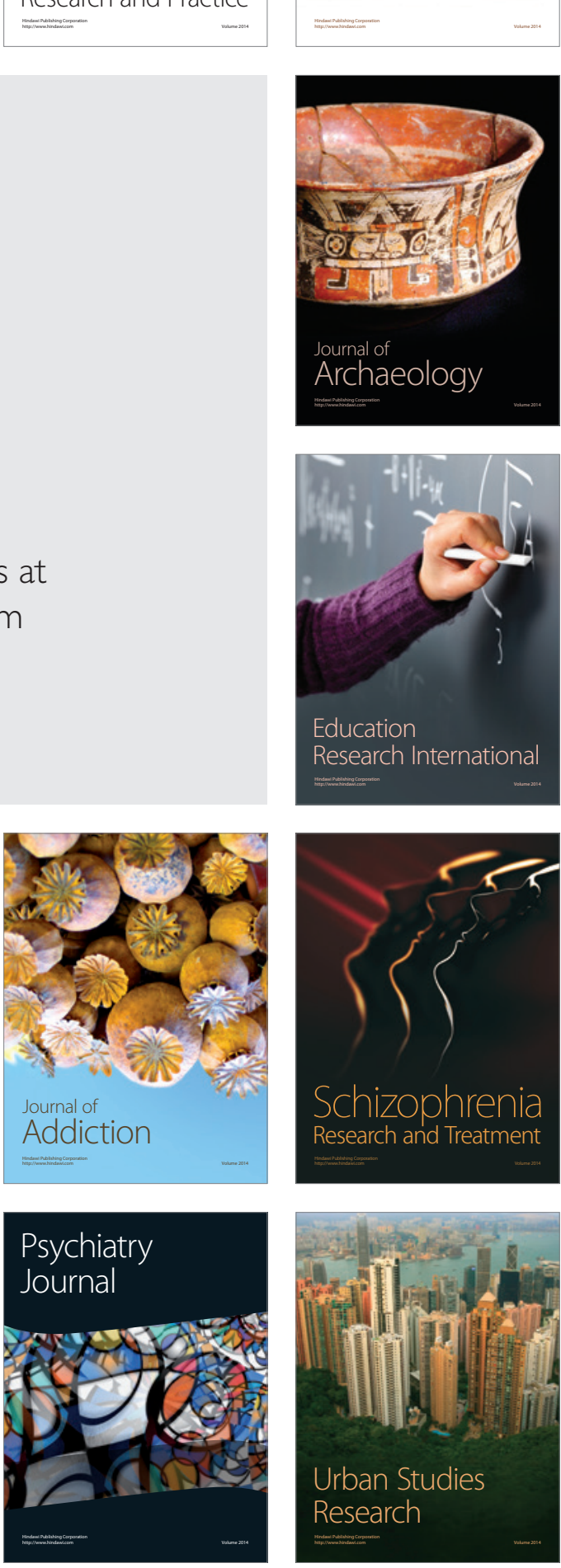